\title{
Formulation of a live bacterial vaccine for stable room temperature storage results in loss of acid, bile and bile salt resistance
}

Article

Accepted Version

Manuscript

Edwards, A. D. and Slater, N. K.H. (2008) Formulation of a live bacterial vaccine for stable room temperature storage results in loss of acid, bile and bile salt resistance. Vaccine, 26 (45). pp. 5675-5678. ISSN 0264-410X doi:

https://doi.org/10.1016/j.vaccine.2008.08.024 Available at https://centaur.reading.ac.uk/8002/

It is advisable to refer to the publisher's version if you intend to cite from the work. See Guidance on citing.

Published version at: http://dx.doi.org/10.1016/j.vaccine.2008.08.024

To link to this article DOI: http://dx.doi.org/10.1016/j.vaccine.2008.08.024

Publisher: Elsevier

All outputs in CentAUR are protected by Intellectual Property Rights law, including copyright law. Copyright and IPR is retained by the creators or other copyright holders. Terms and conditions for use of this material are defined in the End User Agreement.

www.reading.ac.uk/centaur 
Central Archive at the University of Reading

Reading's research outputs online 


\section{Letter to the editor}

Formulation of a live bacterial vaccine for stable room temperature storage results in loss of acid, bile and bile salt resistance

Alexander D. Edwards*, Nigel K. H. Slater**

Department of Chemical Engineering, University of Cambridge

New Museums Site, Pembroke Street, Cambridge, CB2 3RA, UK

*Phone: $<44>1223763969$

Fax: $<44>1223334796$

Email: ade24@cam.ac.uk

**Phone: $<44>1223762953$

Fax: $<44>1223334796$

Email:nkhs2@cam.ac.uk

\section{ABSTRACT}

Live bacterial vaccines have great promise both as vaccines against enteric pathogens and as heterologous antigen vectors against diverse diseases. Ideally, room temperature stable dry formulations of live bacterial vaccines will allow oral vaccination without cold-chain storage or injections. Attenuated Salmonella can cross the intestinal wall and deliver replicating antigen plus innate immune activation signals directly to the intestinal immune tissues, however the ingested bacteria must survive firstly gastric acid and secondly the antimicrobial defences of the small intestine. We found that the way in which cells are grown prior to formulation markedly affects sensitivity to acid and bile. Using a previously published stable storage formulation that maintained over $10 \%$ viability after 56 days storage at room temperature, we found dried samples of an attenuated $S$. typhimurium vaccine lost acid and bile resistance compared to the same bacteria taken from fresh culture. The stable formulation utilised osmotic preconditioning in defined medium plus elevated salt concentration to induce intracellular trehalose accumulation before drying. Dried bacteria grown in rich media without osmotic preconditioning showed more resistance to bile, but less stability during storage, suggesting a trade-off between bile resistance and stability. Further optimization is needed to produce the ultimate room-temperature stable oral live bacterial vaccine formulation.

Key words: Salmonella vaccines, oral delivery, formulation

\section{Main Body:}

Conventional vaccines require refrigerated distribution and storage facilities to retain efficacy and trained practitioners to administer injections. A 'vaccine pill' that conferred protective immunity after oral delivery and was stable at room temperature would revolutionise vaccination programs worldwide. One candidate technology for producing a vaccine pill is heterologous antigen delivery by live bacteria; advanced genetic engineering techniques now allow antigens to be stably maintained in an immunogenic form, for example the model attenuated S. typhimurium vaccine strain SL3261 was modified to utilise the ORT-VAC 
antibiotic free plasmid maintenance system to induce protective immunity against plague with a single oral dose [1].

The di-saccharide trehalose can be used to protect biomolecules and bacteria with waterlike hydrogen bonding in an amorphous 'glassy' dry solid. In addition, osmotic preconditioning to induce intracellular trehalose accumulation was shown to produce dried preparations of attenuated $S$. typhimurium vaccines with exceptional stability at room temperature[2]. However, oral treatment of mice with this dried formulation was unable to protect from infectious challenge, in contrast to oral treatment with bacteria taken directly from liquid culture, suggesting that the drying protocol has a major detrimental effect on subsequent immunogenicity of live bacterial vaccines [2]. The explanation suggested for this loss of immunogenicity was a loss of invasive activity by the bacteria after drying. Enteric pathogens such as salmonella species have evolved complex mechanisms for resisting the cytotoxic effects acid and bile $[3,4]$, and we predicted that another possible detrimental effect of drying bacteria might be to reduce the resistance of bacteria to the harsh conditions found in the stomach or intestine after ingestion. Therefore we compared the acid and bile resistance of osmotically preconditioned dried bacteria to freshly cultured cells.

The model vaccine strain SLDAPD-pUC18I was studied, which is the attenuated $S$. typhimurium strain SL3261 modified to use the ORT-VAC plasmid-free maintenance system [1]. Cells were osmotically preconditioned in order to improve room temperature stability [2]. Osmotically stressing bacteria in rich complex broth such as LB leads to uptake of protectant molecules from the medium, therefore to induce trehalose synthesis defined or minimal medium is required $[2,5]$. Briefly, cells were grown overnight with shaking at $37^{\circ} \mathrm{C}$ in $\mathrm{M} 9$ salts with $1 \mathrm{mM} \mathrm{MgSO} 4,0.1 \mathrm{mM} \mathrm{CaCl}_{2}$ and glucose to $2 \%$, either supplemented with RPMI amino acids to $1 \mathrm{x}$ plus tryptophan, histidine, tryosine, and phenylalanine at a final concentration of $40 \mathrm{mg} / 1$ each plus 2,3-dihydroxy-benzoate and para-hydroxybenzoic acid at $10 \mathrm{mg} / 1 \mathrm{each}$, or enriched with $0.05 \%$ peptone; similar results were obtained with either M9 medium formulation. Osmotic preconditioning was achieved using $0.25-0.5 \mathrm{M} \mathrm{NaCl}$. Cells were harvested, resuspended in PBS with 40\% trehalose plus 1.5\% PVP, and then dried. The density of cells at drying was between $10^{9}-10^{12} \mathrm{cfu} / \mathrm{ml}$, and within this range the cells survived drying regardless of exact density (data not shown and [2]). An initial loss of between 50-80\% of cells was seen at $48 \mathrm{~h}$, but little further loss was seen over 50 days of storage at room temperature in a desiccator, as expected from a previous study using the same protocol to dry the parent strain SL3261 [2]. The pUC18I plasmid was maintained after dry storage for 52 days, as indicated by identical bacterial counts on replicate plates with or without ampicillin, confirming the stability of plasmids maintained using the ORT-VAC system.

As expected [3], SLDAPD taken from liquid culture showed moderate acid resistance and survived $\mathrm{pH}$ down to $\mathrm{pH} 3.3$, but were killed at $\mathrm{pH} 2.6$ (figure 1a). At $\mathrm{pH}$ of 4.2 and above, dried bacteria behaved similarly to bacteria taken from liquid culture; in contrast dried bacteria showed massive loss of viability ( $>1000$-fold) at $\mathrm{pH}$ at 3.8 and below (figure $1 \mathrm{a})$ ). The dried bacteria had no permanent loss of acid resistance, since dried bacteria given 100 minutes to recover in LB medium at 37 degrees showed identical acid resistance to the control LB culture (figure 1a). Note that in this experiment the cell densities tested differed between the dried, control and recovered bacteria, however independent experiments demonstrated that acid and bile resistance was independent of cell density over a broad range (data not shown). This reduction in acid resistance from $\mathrm{pH} 3.3$ to $\mathrm{pH} 4.3$ suggests that dried live bacterial vaccines 
may be killed in the stomach more rapidly than fresh cultured cells.

Enteric delivery results in release into the duodenum, avoiding loss of viability in gastric acid but exposing dried bacteria directly to other defences such as bile. As expected [4], when taken from liquid cultures, SLDAPD growth was unaffected by $2 \%$ bile, although some growth inhibition was seen in $10 \%$ bile (figure $1 \mathrm{~b}$ ). In contrast, dried bacteria showed $>100$-fold loss of viability in $2-10 \%$ bile, and $>20$-fold loss of viability in $0.4 \%$ bile (figure $1 \mathrm{~b}$ ). Furthermore, dried bacteria showed $>100$-fold loss of viability in $3 \mathrm{mM}$ of the purified bile salt deoxycholine (DOC), a dose which showed no significant effect on control cells (figure 1b). The loss of bile and bile salt resistance of dried bacteria was not permanent, because dried bacteria allowed to recover in rich medium showed identical bile resistance to control cells (data not shown). Dried cells also lost resistance to $0.1 \%$ sodium dodecyl sulfate compared to control cells (data not shown), suggesting a general sensitivity to detergents. Because the intestine contains a complex mix of components, it is difficult to estimate the concentration of bile salts that bacteria are exposed to in vivo [4], however total bile salt concentrations in the intestine were measured in the range of $2-10 \mathrm{mM}[6]$. Therefore the observed in vitro sensitivity to $3 \mathrm{mM}$ DOC raises the possibility that dried live bacterial vaccines could be killed if released directly into the intestine using enteric capsules.

To determine if osmotic preconditioning prior to drying affected bile and acid resistance of dried SLDAPD, the acid and bile resistance of osmotically preconditioned dried bacteria was compared with dried cells that had been grown in LB medium. In contrast to the osmotically preconditioned dried cells, which showed $>10$ - to $>500$-fold loss of viability in bile and acid depending on the drying protocol, dried cells that had been grown in rich LB medium retained bile resistance (figure 2a, b). Control cells showed resistance to the acid and bile doses tested (figure 2c). Crucially, the improved bile resistance shown by dried cells grown in rich LB medium was accompanied with a reduced stability when stored at room temperature. LB grown cells survived the initial drying process better, with $47-84 \%$ survival at $\mathrm{d} 5$, in contrast to 23 $26 \%$ survival at $\mathrm{d} 5$ for the osmotically pre-conditioned cells (figure $2 \mathrm{~d}$, e). However, beyond $\mathrm{d} 5$ the osmotically pre-conditioned cells had better stability than cells grown in rich medium. At $\mathrm{d} 35$ the osmotically pre-conditioned cells showed only $7-20 \%$ loss of viability compared to $\mathrm{d} 5$ (depending on drying protocol), and by d52 only $41-42 \%$ loss, demonstrating the high stability of these preparations (figure $2 \mathrm{~d}$ ). In contrast LB grown cells lost $64-83 \%$ live cell number at d 35 compared to $\mathrm{d} 5$, and by d52 83-86\% loss, suggesting a steady decay of these cells (figure $2 \mathrm{e})$. The osmotically preconditioned cells appeared to have a decay rate approximately equivalent to a theoretical sample with a half-life of 20 days, in contrast to the LB grown cells that had a decay rate approximately equivalent to a half life of 60 days (figure $2 \mathrm{~d}$, e). Thus there appears to be a trade-off between optimal stability with poor bile resistance (osmotically preconditioned cells) or, alternatively, reduced stability with better bile resistance (rich medium grown cells).

Bacteria dried under high vacuum in a vacuum chamber (50mTorr at 20 degrees) had marginally less bile and acid resistance than cells dried in a desiccator under low vacuum (approx 0.1 atmosphere at 20 degrees with silica gel desiccant) with similar stability (figure 2A, B, D, E), suggesting that the drying protocol used as well as the growth conditions prior to drying affects bile and acid resistance.

The drying protocols used differed from conventional freeze-drying in that samples were dried under reduced pressure in a dry atmosphere, but temperatures were kept above freezing to 
avoid freeze-injury [2]. However, it is possible that this drying protocol resulted in the observed increase in acid/bile sensitivity, and that freeze-drying would avoid it. Replicate samples of cells were frozen in parallel to drying and the stability and acid/bile resistance of frozen and dried samples compared. Compared to dried samples, freeze-thawed cells showed similar acid and bile resistance, with the exception of cells grown in rich medium that had better acid resistance after freeze-thaw than after drying (figure 2a,b). The speed of freezing had some influence on bile and acid resistance, with cells frozen rapidly in liquid nitrogen having better resistance than slower shelf freezing (figure 2a,b). The trehalose/PVP excipient provided good cryoprotection and all frozen samples showed excellent stability when stored at -80 (figure $2 \mathrm{~d}, \mathrm{e})$. Since frozen cells also had lost acid and bile resistance, conventional freeze-drying will also result in dried preparations with high acid and bile susceptibility.

To determine if increased $\mathrm{NaCl}$ concentrations prior to drying were responsible for the loss of acid and bile resistance after drying, cells were grown in $\mathrm{M} 9$ with varying $\mathrm{NaCl}$ concentration. Increased osmolarity can reduce growth rate, and the growth stage can affect drying tolerance, so equivalent $30 \mathrm{ml}$ cultures were taken after $24 \mathrm{~h}$ growth, harvested and resuspended in $0.8 \mathrm{ml}$ excipient, and cell yields were compared. $\mathrm{NaCl}$ concentrations of 250 350 had only 2 to 4 -fold reduced cell yields, but increasing $\mathrm{NaCl}$ to $450 \mathrm{mM}$ resulted in 70 -fold fewer cells compared to M9 alone (figure 3f). Cells grown in $\mathrm{NaCl}$ concentrations of 250-350 $\mathrm{mM}$ also showed growth rates measured by OD600 with less than one doubling in $2 \mathrm{~h}$, suggesting the cells had reached stationary phase (data not shown). Cells grown in enriched M9 without added $\mathrm{NaCl}$ and dried showed good acid and bile resistance, whereas increasing $\mathrm{NaCl}$ concentration to 250-350 $\mathrm{mM}$ resulted in reduced bile and acid resistance (figure $3 \mathrm{f}$ ). The reduced bile and acid resistance seen at $250-350 \mathrm{mM} \mathrm{NaCl}$ is unlikely to be due to alteration in growth rates, since the final cell yield was only 2 - to 4 -fold reduced. Cells grown in $450 \mathrm{mM}$ $\mathrm{NaCl}$ had very poor acid and bile tolerance, however, which could be due to reduced growth rates or another effect. The reduced growth did not affect survival after drying, which was good in all cell conditions (figure $2 \mathrm{f}$ ). Addition of $\mathrm{NaCl}$ up to $500 \mathrm{mM}$ in rich $\mathrm{LB}$ broth did not affect bile or acid tolerance of dried cells (data not shown).

\section{Conclusions}

We found that depending on the method used to prepare dried bacteria, drying appears to disable the resistance to acid and bile that $S$. typhimurium evolved to survive after ingestion. There appears to be a trade-off between optimal stability during storage with poor bile resistance (osmotically preconditioned cells) or, alternatively, reduced storage stability with better bile resistance (rich medium grown cells); furthermore dried cells produced in any condition showed significantly decreased acid resistance. We feel the success of current efforts to produce stable 'vaccine pills' that deliver heterologous antigens using live bacterial vectors may depend on resolving this issue of survival of the bacteria post ingestion. We are conducting further studies to elucidate the mechanism of this effect. Finally, in order to determine how the increased bile and acid sensitivity caused by drying affects oral vaccine delivery, testing of infectious doses of dried bacteria in model organisms is needed. Hopefully, these studies will result in improved formulations that improve oral survival whilst maintaining stability.

\section{Acknowledgements}

Rocky Cranenburgh, Matthew Leckenby, David Thatcher at Cobra Biomanufacturing provided the SLDAPD-pUC18I model vaccine strain and gave helpful input to discussions and comments on the manuscript. Simon Cutting at Royal Holloway University of London gave 
helpful input to discussions and comments on the manuscript. The work was funded by grant project M0024E from the Technology Strategy Board and the UK Engineering and Physical Sciences Research Council (EPSRC). The Technology Strategy Board is a business-led executive non-departmental public body, established by the government. Its mission is to promote and support research into, and development and exploitation of, technology and innovation for the benefit of UK business, in order to increase economic growth and improve the quality of life. It is sponsored by the Department for Innovation, Universities and Skills (DIUS).

\section{References}

[1] Garmory HS, Leckenby MW, Griffin KF, Elvin SJ, Taylor RR, Hartley MG, et al. Antibiotic-free plasmid stabilization by operator-repressor titration for vaccine delivery by using live Salmonella enterica Serovar typhimurium. Infect Immun 2005 Apr;73(4):2005-11.

[2] Bullifent HL, Dhaliwal K, Howells AM, Goan K, Griffin K, Lindsay CD, et al. Stabilisation of Salmonella vaccine vectors by the induction of trehalose biosynthesis. Vaccine 2000 Dec 8;19(9-10):1239-45.

[3] Foster JW. Escherichia coli acid resistance: tales of an amateur acidophile. Nat Rev Microbiol 2004 Nov;2(11):898-907.

[4] Begley M, Gahan CG, Hill C. The interaction between bacteria and bile. FEMS Microbiol Rev 2005 Sep;29(4):625-51.

[5] Le Rudulier D, Strom AR, Dandekar AM, Smith LT, Valentine RC. Molecular biology of osmoregulation. Science 1984 Jun 8;224(4653):1064-8.

[6] Northfield TC, McColl I. Postprandial concentrations of free and conjugated bile acids down the length of the normal human small intestine. Gut 1973 Jul;14(7):513-8.

\section{Figure legends}

Figure 1: Osmotically pre-conditioned dried bacteria show reduced resistance to acid, bile and bile salts.

A: The acid resistance of dried osmotically preconditioned cells was compared to control and recovered dried cells by incubation in $\mathrm{LB}$ acidified with $\mathrm{HCl}$ to the indicated $\mathrm{pH}$ for $1 \mathrm{~h}$ at $37^{\circ} \mathrm{C}$, followed by dilution and plating to determine colony forming units (cfu). Dried cells were osmotically preconditioned by overnight culture in $\mathrm{M} 9$ medium with $0.25 \mathrm{M} \mathrm{NaCl}$ then dried in a vacuum desiccator in $\mathrm{PBS} / 40 \%$ trehalose $/ 1.5 \% \mathrm{PVP}$. Control cells were grown in rich medium for $4 \mathrm{~h}$ from a glycerol stock, and recovered cells were dried cells rehydrated in rich medium and cultured for 100 minutes. Relative $\mathrm{CFU} / \mathrm{ml}$ indicates the equivalent bacterial count calculated to the original volume before drying or volume of control sample before dilution in test medium; all samples were diluted at least 50x into test media to ensure dilution of the drying excipient. Note that the control and recovered cell samples were tested at a lower starting density than the dried cells, as seen in the $\mathrm{pH} 7$ condition; resistance to acid and bile was independent of density (data not shown). Similar loss of acid resistance by dried cells was seen in more than three independent experiments. All error bars are shown and represent standard error of more than 5 replicate colony counts.

B: The bile and bile salt resistance of dried osmotically preconditioned cells was compared to control cells by incubation in LB with the indicated concentrations of ox bile or deoxycholine (DOC) for $1 \mathrm{~h}$ at $37^{\circ} \mathrm{C}$, followed by dilution and plating. Dried cells were osmotically preconditioned by overnight culture in $\mathrm{M} 9$ medium with $0.3 \mathrm{M} \mathrm{NaCl}$ then dried in $\mathrm{PBS} / 40 \%$ 
trehalose/1.5\%PVP. Similar bile and bile salt resistance was seen in more than three independent experiments. All error bars are shown and represent standard error of more than 5 replicate colony counts.

Figure 2: Effect of growth condition before drying on acid or bile resistance and stability during storage.

A-E: Bacteria were either osmotic preconditioned by culture overnight in M9 medium plus $0.5 \mathrm{M} \mathrm{NaCl}(\mathrm{A}, \mathrm{D})$, or cultured overnight in rich LB medium $(\mathrm{B}, \mathrm{E})$, before drying or freezing as indicated and stored at room temperature in a desiccator (dried samples) or at -80 (frozen samples). A, B: After 5d storage, dried cells were rehydrated in LB at pH 7, LB at pH 3.8, or $5 \%$ bile and cultured for $1 \mathrm{~h}$ followed by dilution and plating to determine live cell counts. $\mathbf{C}$ : Control cells were cultured in LB for 3 h prior to testing alongside dried cells in A and B. D, E: Stored samples were diluted and counted before drying or freezing, or after 5, 35 or 52 days storage as indicated. Dashed grey lines indicate theoretical decay of samples with half lives of 20 or 60 days for comparison. F: Cells were prepared in M9 medium with the indicated concentration of $\mathrm{NaCl}$ before drying, then tested for acid and bile resistance for 1 hour followed by dilution and plating. The cell yield before drying is also presented, to demonstrate the effect of $\mathrm{NaCl}$ concentration on cell growth. 